Удк $547.3+615.3$

\title{
МОДИФИКАЦИЯ ОСНОВАНИЙ ШИФФА ГОССИПОЛА С ГЕТЕРОЦИКЛИЧЕСКИМИ АМИНАМИ
}

\author{
(C) A.X. Хаитбаeв
}

\author{
Национальный университет Узбекистана им. М. Улугбека, Вузгородок, \\ Ташкент, 100174 (Республика Узбекистан), e-mail: polyphenol-10@yandex.ru
}

С помощью МАСГК (моноаммониевой солью глицирризиновой кислотой), а также получения металлокомплексов с $\left(\mathrm{Cu}\left(\mathrm{CH}_{3} \mathrm{COO}\right)_{2} \cdot \mathrm{H}_{2} \mathrm{O}\right.$ и $\left.\mathrm{Ni}\left(\mathrm{CH}_{3} \mathrm{COO}\right)_{2} \cdot 4 \mathrm{H}_{2} \mathrm{O}\right)$ были модифицированы ранее синтезированные азометиновые производные госсипола с аминосоединениями гетероциклической природы. С помощью методов УФ- и ИКспектроскопии были изучены строение и индивидуальность синтезированных комплексов.

Ключевые слова: МАСГК, металлокомплексы, супрамолекулярные комплексы.

\section{Введение}

Изначально известно, что водорастворимые вещества проявляют более активные биологические свойства, чем нерастворимые [1], этот феномен может объяснятся большей биодоступностью водорастворимых препаратов в организме. Поэтому целью настоящей работы являлась модификация ранее синтезированных производных госсипола с гетероциклическим аминосоединениями, такими как аденин, 2-аминотиазол, 2-амино-4-метил-5-бром-6-гидроксопиримидин и др. Для модификации использовали два способа, получение супрамолекулярных комплексов с МАСГК (моноаммониевой солью глицирризиновой кислоты), а также получение металлокомплексов с $\left(\mathrm{Cu}\left(\mathrm{CH}_{3} \mathrm{COO}\right)_{2} \cdot \mathrm{H}_{2} \mathrm{O}\right.$ и $\left.\mathrm{Ni}\left(\mathrm{CH}_{3} \mathrm{COO}\right)_{2} \cdot 4 \mathrm{H}_{2} \mathrm{O}\right)$ [2].

\section{Экспериментальная часть}

Строение и индивидуальность всех синтезированных соединений были изучены с помощью УФ- и ИК-спектроскопии. УФ-спектр изучали с помощью СФ-26 спектрофотометра, ИК-спектр снимали с помощью прибора UR-20 (толщина кюветы 10 мм, в виде таблеток с KBr). С помощью КФК-3 определяли наличие металлов в составе синтезированных металлокомплексов. Температура плавления веществ определяли с помощью специальных устройств.

\section{Результаты и обсуждение}

Главной причиной создания лекарственных средств на основе глицирризиновой кислоты (ГК) и ее производных является ее хорошо выраженное солюбилизирующее свойство. Многие плохорастворимые или даже нерастворимые в воде субстанции лекарственных препаратов (аспирин, индометацин, госсипол, рагосин и др.) хорошо растворяются в воде в присутствии даже небольшого количества ГК. Причиной солюбилизирующих свойств этого природного вещества является, естественно, межмолекулярное взаимодействие, возникающее при контакте ГК с различными органическими веществами в растворе [3]. Методом ${ }^{13} \mathrm{C}-Я М Р$ была показана циклическая конформация ГК. Как полагают, стабильность мицеллярного состояния ГК обусловлена возможностью внутримолекулярного взаимодействия карбоксильных групп агликона и глюкуроновой

Хаитбаев Алишер Хамидович - заведующий межвузовской лабораторией «Физико-химические методы исследования», кандидат химических наук, еmail: polyphenol-10@yandex.ru кислоты, расположенной в конце углеводного фрагмента [3]. При этом создается внутрисферное пространство, удобное для образования соединений включения или комплексов типа «гость - хозяин». Комплексообразование идет за счет кооперативных 
водородных связей при клатратообразовании типа «гость - хозяин», где в роли «хозяина» выступает кислота, а в роли «гостя»- лекарственные соединения [4].

В связи с этим был получен супрамолекулярный комплекс МАСГК с соответствующими гетероциклическими аминосоединениями в мольном соотношении $2: 1$. Синтез был проведен по следующей схеме:

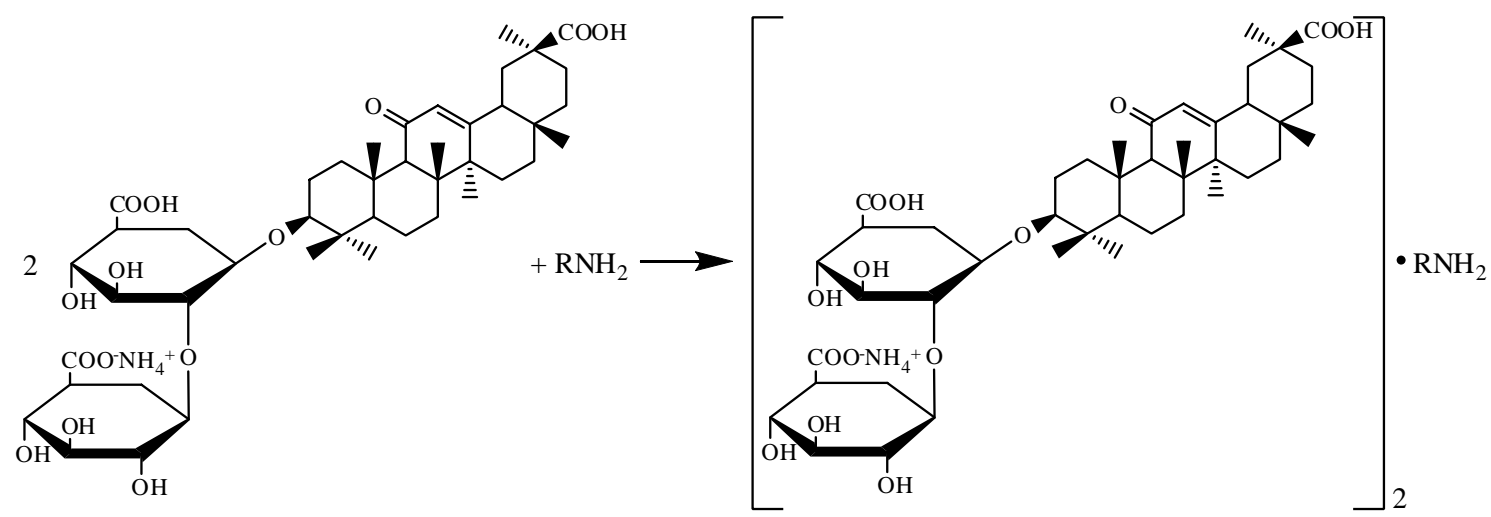

Полученные супрамолекулярные комплексные соединения оснований Шиффа с МАСГК имели оттенки от желтого до оранжевого цветов. Ход реакции получения супрамолекулярных комплексов контролировали ТСХ. Некоторые физико-химические свойства полученных супрамолекулярных комплексов приведены в таблице 1. Полученные комплексы X-XVIII растворимы в воде.

В литературе приводятся данные о том, что металлокомплексы органических веществ, содержащие в своем составе металлы d-подгрупп, проявляют выраженную биологическую активность против бактерий, грибков, микробов и др. [5]. Основываясь на этих данных, мы синтезировали соответствующие металлокомплексы оснований Шиффа с двумя $\left(\mathrm{Cu}\left(\mathrm{CH}_{3} \mathrm{COO}\right)_{2} \cdot \mathrm{H}_{2} \mathrm{O}\right.$ и $\left.\mathrm{Ni}\left(\mathrm{CH}_{3} \mathrm{COO}\right)_{2} \cdot 4 \mathrm{H}_{2} \mathrm{O}\right)$ солями. Металлокомплексы соответствующих оснований Шиффа госсипола с данными ацетатами металлов можно изобразить с помощью следующей схемы:

$$
2 \Gamma \Pi-\mathrm{R}+\mathrm{Me}(\mathrm{CH} 3 \mathrm{COO})_{2} \cdot 4 \mathrm{H}_{2} \mathrm{O}=\mathrm{Me}(\Gamma \Pi-\mathrm{R})_{2}\left(\mathrm{CH}_{3} \mathrm{COO}\right)_{2} \cdot 2 \mathrm{H}_{2} \mathrm{O}+2 \mathrm{H}_{2} \mathrm{O} .
$$

Ход реакции контролировали с помощью ТСХ. Некоторые физико-химические свойства полученных металлокомплексов приведены в таблице 2. Металлокомплексы растворимы в ДМСО, ДМФА. С помощью КФК-3 определяли наличие ионов $\mathrm{Cu}^{2+}$ в составе синтезированного металлокомплекса.

Полученные данные доказывают наличие ионов $\mathrm{Cu}^{2+}$ в составе синтезированного металлокомплекса.

Строение, состав и индивидуальность синтезированных комплексов были изучены с помощью УФи ИК-спектроскопии (рис. 1-3). Для этого сравнивали данные спектров оснований Шиффа госсипола с модифицированными производными этих соединений.

При сравнении спектров можно увидеть уширение сигналов, соответствующее ОН-группам, что свидетельствует об образовании межмолекулярных водородных (в случае супрамолекулярного комплекса) и донорно-акцепторных (в случае металлокомплексов) связей. Аналогично исследовали строение и индивидуальность других синтезированных комплексов.

Таблица 1. Некоторые физико-химические свойства полученных супрамолекулярных комплексов

\begin{tabular}{c|c|c|c|c|c}
\hline Соединение & $\begin{array}{c}\text { Супрамолекулярный } \\
\text { комплекс }\end{array}$ & $\mathrm{T}_{\text {пл., }}{ }^{\circ} \mathrm{C}$ & $\mathrm{R}_{\mathrm{f}}{ }^{*}$ & Выход, \% & Цвет \\
\hline X & I + МАСГК & $205-207$ & 0,61 & 82,4 & Оранжевый \\
XI & II + МАСГК & $215-217$ & 0,63 & 97,6 & Темно-желтый \\
XII & III + МАСГК & $201-204$ & 0,65 & 95,8 & Красный \\
XIII & IV + МАСГК & $217-219$ & 0,55 & 89,4 & Темно-желтый \\
XIV & V+ МАСГК & $271-273$ & 0,61 & 97,8 & Желтый \\
XV & VI+ МАСГК & $222-224$ & 0,59 & 66,1 & Желтый \\
XVI & VII+ МАСГК & $213-215$ & 0,65 & 79,1 & Желтый \\
XVII & VIII+ МАСГК & $190-192$ & 0,67 & 84,5 & Желтый \\
XVIII & IX+ МАСГК & $209-211$ & 0,70 & Темно-желтый \\
\hline
\end{tabular}

Примечания. Мольное соотношение $-1: 4$; *Система: бензол - ацетон $(2: 1)$ 
Таблица 2. Некоторые физико-химические свойства полученных металлокомплексов

\begin{tabular}{c|c|c|c|c}
\hline Соединение & Синтезированный комплекс & $\mathrm{T}_{\text {пл, }}{ }^{\circ} \mathrm{C}$ & $\mathrm{R}_{\mathrm{f}}$ & Выход, \% \\
\hline XIX & $\mathrm{I}+\mathrm{Cu}\left(\mathrm{CH}_{3} \mathrm{COO}\right)_{2}$ & $268-270$ & $0,59^{* *}$ & $0,71^{* *}$ \\
& & & $0,32^{*}$ & 77,1 \\
XX & $\mathrm{II}+\mathrm{Cu}\left(\mathrm{CH}_{3} \mathrm{COO}\right)_{2}$ & 300 & $0,59^{* *}$ & 83,2 \\
& & & $0,47^{*}$ & $0,78^{* *}$ \\
XXI & $\mathrm{III}+\mathrm{Ni}\left(\mathrm{CH}_{3} \mathrm{COO}\right)_{2}$ & $210-212$ & $0,39^{*}$ & 69,3 \\
& & & $0,67^{* *}$ & \\
\hline
\end{tabular}

Примечания. Мольное соотношение - $2: 1$; *Система: гексан - ацетон $(2: 1)$; ** гексан - ацетон $(2: 1,5)$

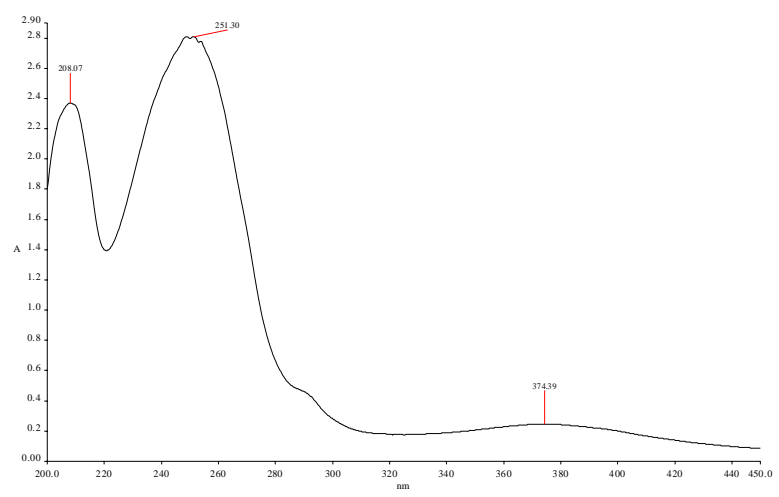

Рис. 1. УФ-спектр супрамолекулярного комплекса основания Шиффа госсипола с аденином и МАСГК

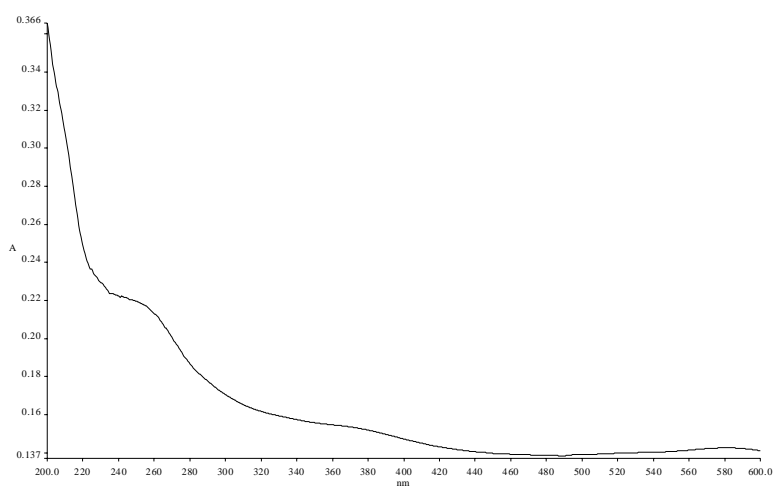

Рис. 2. УФ-спектр металлокомплекса основания Шиффа госсипола с аденином и $\mathrm{Cu}\left(\mathrm{CH}_{3} \mathrm{COO}\right)_{2}$

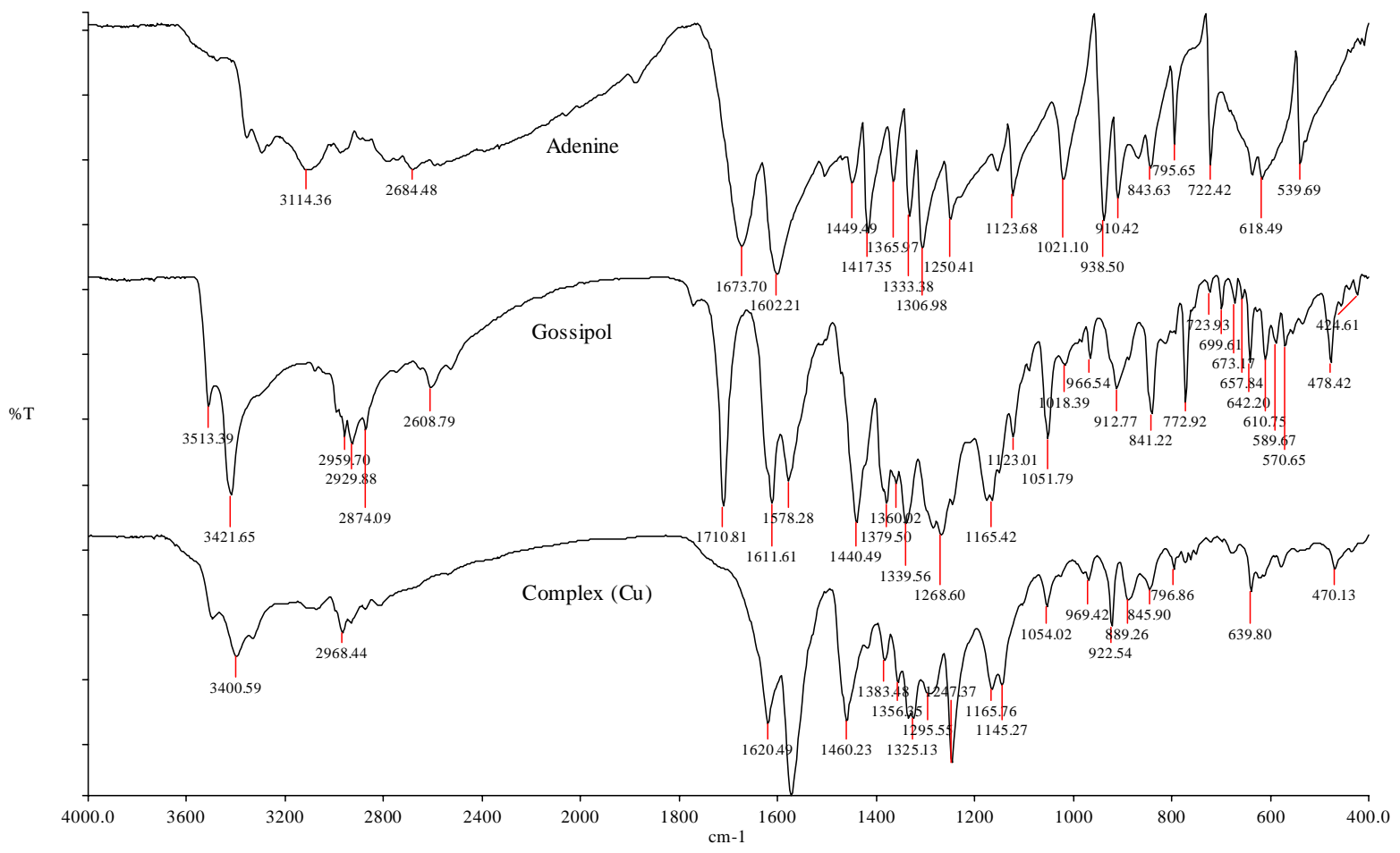

Рис. 3. ИК-спектры аденинна (1), госсипола (2) и металлокомплекса основания Шиффа госсипола с аденином и $\mathrm{Cu}\left(\mathrm{CH}_{3} \mathrm{COO}\right)_{2}(3)$ 


\section{Заключение}

Таким образом, с использованием моноаммониевой соли глицирризиновой кислоты и солей $\mathrm{Cu}\left(\mathrm{CH}_{3} \mathrm{COO}\right)_{2} \cdot \mathrm{H}_{2} \mathrm{O}$ и $\mathrm{Ni}\left(\mathrm{CH}_{3} \mathrm{COO}\right)_{2} \cdot 4 \mathrm{H}_{2} \mathrm{O}$ были модифицированы ранее синтезированные азометиновые производные госсипола с аминосоединениями гетероциклической природы. Методами УФ- и ИКспектроскопии показано строение синтезированных комплексов.

\section{Сиисок литературь}

1. Толстикова Т.Г., Толстиков А.Г., Толстиков Г.А. На пути к низкодозным лекарствам // Вестник РАН. 2007. T. 77, № 10. С. 867-874.

2. Muhanned Jawad Kadhim Al-Assadi. Synthesis and Characterization of $\mathrm{Ni}^{2+}$ and $\mathrm{Cu}^{2+}$ Schiff-base Complexes and Their Study for Electrical Properties // Journal of Basrah Researches (Sciences). 2011. Vol. 37, N3A. Pp. 104-110.

3. Толстиков Г.А., Балтина Л.А., Щульц Э.Э., Покровский А.Г. Глицирризиновая кислота // Биоорганическая химия. 1997. Т. 23, №9. С. 691-709.

4. Abdullaev N.D., Dalimov D.N., Faskhutdinov M.F., Levkovich M.G. Mechanisms of Complexation of Glycyrrhizinic Acid with some Medicinal Preparations // 6th International Symposium on the Chemistry of Natural Compounds (SCNC). Ankara, 2005.

5. Joshi S., Pawar V., Uma V. Antibacterial and Antioxidant Properties of Mn(II), Co(II), Ni(II) and Zn(II) Complex of Schiff base derived from Cephalexin // Research Journal of Pharmaceutical, Biological and Chemical Sciences. 2011. Vol. 2, N2. Pp. 61-70.

Khaitbaev A.Kh. MODIFICATION OF PREVIOUSLY RECEIVED SCHIFF BASES OF GOSSYPOL WITH HETEROCYCLIC AMINES

National University of Uzbekistan named after M. Ulugbek, Tashkent, 100174, (Uzbekistan),

e-mail: polyphenol-10@yandex.ru

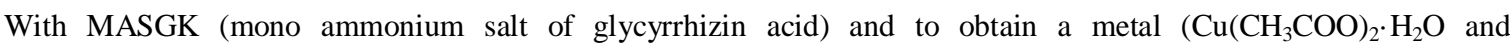
$\left.\mathrm{Ni}\left(\mathrm{CH}_{3} \mathrm{COO}\right)_{2} \cdot 4 \mathrm{H}_{2} \mathrm{O}\right)$ have been modified previously synthesized azomethin derivatives of gossypol with amino compounds heterocyclic nature. Using the methods of UV and IR spectroscopy were studied the structure and identity of the synthesized complexes.

Keywords: MASGK, metal complexes, supramolecular complexes.

\section{References}

1. Tolstikova T.G., Tolstikov A.G., Tolstikov G.A. Vestnik RAN, 2007, vol. 77, no. 10, pp. 867-874. (in Russ.).

2. Muhanned Jawad Kadhim Al-Assadi. Journal of Basrah Researches (Sciences), 2011, vol. 37, no. 3A, pp. 104-110.

3. Tolstikov G.A., Baltina L.A., Shchul'ts E.E., Pokrovskii A.G. Bioorganicheskaia khimiia, 1997, vol. 23, no. 9, pp. 691-709. (in Russ.).

4. Abdullaev N.D., Dalimov D.N., Faskhutdinov M.F., Levkovich M.G. Mechanisms of Complexation of Glycyrrhizinic Acid with some Medicinal Preparations // 6th International Symposium on the Chemistry of Natural Compounds (SCNC). Ankara, 2005.

5. Joshi S., Pawar V., Uma V. Research Journal of Pharmaceutical, Biological and Chemical Sciences, 2011, vol. 2, no. 2, pp. 61-70. 